\title{
STUDIES OF THE VENTILATION-PERFUSION RELATIONSHIPS \\ IN THE LUNGS OF SUBJECTS WITH CHRONIC PULMONARY EMPHYSEMA, FOLLOWING A SINGLE INTRAVENOUS INJECTION OF RADIOACTIVE KRYPTON $\left(\mathrm{KR}^{85}\right)$. I. PRESENTATION AND VALIDATION OF A THEORETICAL MODEL *
}

\author{
By H. P. GURTNER, $†$ W. A. BRISCOE AND A. COURNAND
}

\author{
(From the Department of Medicine, Columbia University College of Physicians and Surgeons \\ and the Cardio-Pulmonary Laboratory of the First Medical and Chest Services, Columbia \\ University Division, Bellevue Hospital, New York, N. Y.
}

(Submitted for publication December 28, 1959; accepted March 1, 1960)

The study of the elimination of an inert gas from the lungs of human individuals has proven a useful tool in the determination of ventilation patterns $(1,2)$. In particular it could be demonstrated that the lungs of emphysematous patients can be conceived as being composed of at least two different compartments, i.e., a relatively small space with good ventilation and a relatively large space with poor ventilation (3).

In an attempt to establish the ventilationperfusion relationship in the different lung compartments of patients suffering from pulmonary emphysema, Briscoe $(4,5)$ correlated the ventilation and volume patterns with the oxygen saturation of mixed arterial blood: a very large and poorly ventilated air compartment in the emphysematous lung was shown to be relatively underperfused with blood (6).

In order to check on these findings it was decided to measure the distribution of ventilation and perfusion (especially the latter) in emphysema with an independent technique. Dissolved radioactive krypton $\left(\mathrm{Kr}^{85}\right)$ was injected intravenously and its rate of disappearance was measured in both expired air and arterial blood. A preliminary report of this work has been published (7). The purpose of this paper is to describe the behavior of intravenously injected krypton in the emphysematous subject and to show how this behavior may be used to determine the distribution of perfusion in the lung. With

\footnotetext{
* This investigation was supported by a research grant [Public Health Service Grant H-2001(C)] from the National Heart Institute, Bethesda, Md.

$\dagger$ Fellow of the Swiss Academy of Medicine, Fellow in Medicine of Columbia University. Supported by the American-Swiss Foundation for Scientific Exchange.
}

this objective we present 1) a theoretical model of the lungs and tissues of the emphysematous man under these conditions; 2) a mathematical solution of the equations of the three-compartment analog thus depicted; 3) a comparison of the predicted theoretical curves with the experimental curves which are actually obtained; 4) three methods for interpreting experimental data in terms of the dimensions, ventilation and blood perfusion of several lung compartments: $a$ ) an exact method, which might be applicable under optimal conditions to experiments with sampling at three sites, and $b$ ) two approximate methods, applicable to data limited as to time and number of sampling sites as they usually are in practice.

\section{THEORETICAL MODEL: THREE COMPARTMENT ANALOG OF THE BODY IN EMPHYSEMA}

The sequence of events which take place after the rapid injection of a dissolved tracer gas of low solubility into a systemic vein of a human subject is best understood if the behavior of a model, essentially analogous to the experimental situation, is studied. The experiment begins with the rapid injection of radioactive $\mathrm{Kr}^{85}$ dissolved in saline (8). The usual site of injection is a large vein as near as possible to the heart; the optimal site is the right heart itself which was used in the studies reported here. As the slug of dissolved $\mathrm{Kr}^{85}$ passes through the pulmonary capillaries almost all of it diffuses into the alveolar gas spaces because of the relative insolubility of krypton (8). In emphysema these spaces vary greatly in their degree of ventilation. A small part of the lung is well ventilated. That fraction of the injected $\mathrm{Kr}^{85}$ which is carried in 

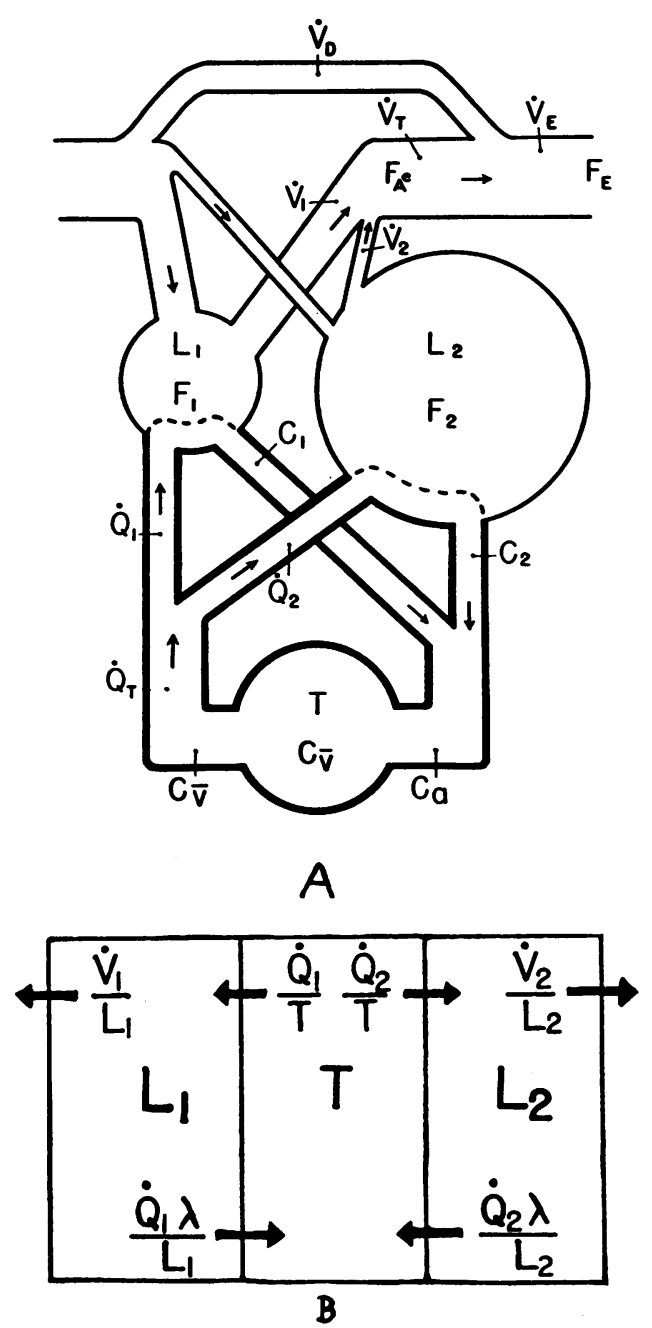

Fig. 1. Model simulating the washout of intraVENOUSLY INJECTED $\mathrm{KR}^{85}$ IN PATIENTS WITH PULMONARY EMPHYSEMA. For explanation of symbols see text. 1A shows the three chambers under consideration and the flows between them; 1B the fractional rate constants, indicated by arrows, are used in the solution of the differential equations 2,3 and 4 .

the blood to, and deposited in the well ventilated air spaces, is rapidly eliminated in 2 to 5 minutes. A much larger part of the lung is homogeneously very poorly ventilated. The krypton deposited in these air spaces at the time of injection is still being eliminated in appreciable amounts in the gas expired from them 20 minutes later. The end capillary blood leaving both groups of alveoli is considered at all times to contain krypton at the same partial pressure as the alveolar gas. The quantities of krypton in solution in blood are relatively small, compared to the quantities in the gas phase $[\lambda=0.051$ (9) $]$. The end capillary blood from the differently ventilated lung spaces mixes in the arterial blood stream which then passes to the tissues. In the first few minutes after injection, arterial blood contains more $\mathrm{Kr}^{85}$ than the tissues, and the tissue $\mathrm{Kr}^{85}$ concentration rises. As krypton is ventilated out of the lung spaces, arterial $\mathrm{Kr}^{85}$ concentration falls. After reaching a peak a few minutes after injection, tissue $\mathrm{Kr}^{85}$ concentration falls. Venous $\mathrm{Kr}^{85}$ concentration is considered at all times to be equal to that in the tissues. Krypton from the tissues is carried in venous blood to the lungs, redeposited into alveolar gas, and eliminated in ventilation, until eventually no $\mathrm{Kr}^{85}$ remains in the body.

The simplest model, therefore, for the quantitative considerations of this situation consists of three reservoirs or mixing chambers, exchanging krypton by means of the blood stream, and with two of these reservoirs eliminating $\mathrm{Kr}^{85}$ through ventilatory channels into an infinite space. This model is schematically depicted in Figures $1 \mathrm{~A}$ and $1 \mathrm{~B}$. The three mixing chambers are the well ventilated small lung compartment $\left(\mathrm{L}_{1}\right)$, the poorly ventilated large lung compartment $\left(\mathrm{L}_{2}\right)$ and the tissue space (T). Three-compartment systems, both closed $(10,11)$ and open $(12-14)$, have previously been described; the algebraic treatment is therefore abbreviated here. It is noteworthy that in the present model direct access is limited to one compartment $(T)$. The output from the two lung compartments $\left(\mathrm{L}_{1}\right.$ and $\mathrm{L}_{2}$ ) cannot be measured individually; it is possible, however, to measure their combined output which is reflected in arterial blood and expired air. Arterial blood is the mixture of the blood equilibrated in the two lung compartments, weighted by their respective flows. Mixed expired alveolar gas is the mixture of the gas in the two lung compartments, weighted by their respective ventilations. Expired gas is mixed expired alveolar gas with its krypton diluted by inspired gas from the dead space. In the model calculations the dead space is assumed to be zero, in which case mixed expired alveolar and expired gas are the same. Another specific feature of this model is the combination of a liquid and a gaseous carrier phase. This required knowledge of $a$ ) the solubility characteristics of the tracer 
gas, and $b$ ) the difference in counting efficiency of liquid and gaseous specimens containing tracer (9).

The description of the emphysematous patient's body in terms of only three compartments did not originate de novo but from studies of their behavior. Although there are probably differences among the well ventilated alveoli $\left(\mathrm{L}_{1}\right)$ and among the various tissues included in the tissue space $(T)$, it appears from nitrogen washout studies that in severe emphysema there is often a surprising lack of variation among the alveoli in the poorly ventilated group $\mathrm{L}_{2}(6)$. This group of alveoli constitutes the major reservoir for krypton, and has a dominant influence on the behavior of injected krypton; so it is justifiable, and a very useful simplification, to ignore the variation in $L_{1}$ and $T$ and to consider the body as if it consisted of only three compartments.

\section{MATHEMATICAL DESCRIPTION OF THE BEHAVIOR OF THE MODEL}

Having described the model in physiological terms which characterize the emphysematous patient, our next aim is to construct theoretical curves for comparison with the data actually obtained in patients. Furthermore, these theoretical curves will be analyzed by various approximate methods easily applicable to patients in order to determine the error in these methods. The construction of the curves necessitates some rather lengthy calculations, and before proceeding to the comparison between predicted and observed behavior it is necessary to indicate in outline the assumptions (Section IIA), the algebraic principles (Section IIC), and the numerical values of the coefficients in our examples (Section IID).

\section{A. Assumptions}

The theoretical model is applied to experimental situations with the following assumptions:

1. Blood and gas leaving a mixing chamber are in complete equilibrium with this chamber. Deviations from this are believed to be insignificant as regards inert gas exchange in the lung $(15,16)$ with which this study is mainly concerned. The quantities exchanged in the tissues are of secondary importance and if this assumption does not apply here it has no important effect on our conclusions.

2. Ventilation and perfusion are continuous rather than periodic. There is no rebreathing of $\mathrm{Kr}^{85}$ by one lung compartment from the respiratory dead space of gas expired from a differently ventilated lung compartment. This assumption has no important effect on the conclusions when there are large differences between the ventilation of the different lung compartments, as is the case in emphysema. Expired gas is mixed expired alveolar gas diluted by a constant flow of inspired gas, the dead space ventilation. Since this dead space ventilation has no effect on the system except to reduced expired concentrations to a constant fraction of mixed expired alveolar concentrations, it has been considered to be zero in our theoretical cases; as explained later it must be allowed for in practice.

3. The solubility of $\mathrm{Kr}^{85}(\lambda)$ is the same for blood and body tissues.

4. The amount of $\mathrm{Kr}^{85}$ in the blood is negligible.

\section{B. Explanation of symbols}

Some of the symbols have already been referred to. It is convenient at this point to give a complete list of the symbols used subsequently, with units of each indicated.

Gas volumes (liters): $\mathrm{L}_{1}$ in well ventilated alveoli; $\mathrm{L}_{2}$ in poorly ventilated alveoli, $\mathrm{L}_{\mathrm{T}}=\mathrm{L}_{1}+\mathrm{L}_{2}$. Tissue volume (liters) : T. Gas flows (liters per minute): $\dot{\mathrm{V}}_{1}$ in well ventilated alveoli; $\dot{\mathrm{V}}_{2}$ in poorly ventilated alveoli; $\dot{\mathrm{V}}_{\mathrm{T}}=\dot{\mathrm{V}}_{1}$ $+\dot{V}_{2} ; \dot{V}_{E}$ expired ventilation; $\dot{V}_{D}$ dead space ventilation. Blood flows (liters per minute): $\dot{Q}_{1}$ in well ventilated alveoli ; $\dot{Q}_{2}$ in poorly ventilated alveoli; $\dot{Q}_{\mathrm{T}}=\dot{Q}_{1}+\dot{Q}_{2}$.

Quantities of $K^{r^{85}}$ (counts per minute): $\mathrm{X}$ in $\mathrm{L}_{1}, \mathrm{Y}$ in $\mathrm{L}_{2}$, I injected. Concentrations of krypton in gas phase (counts per minute per liter): $F_{1}$ in well ventilated alveoli; $F_{2}$ in poorly ventilated alveoli; $\mathrm{F}_{\mathrm{E}}$ in expired air. $\quad \mathrm{F}_{\mathrm{A}}{ }^{\mathrm{e}}$ in mixed expired alveolar gas. Concentration of krypton in blood phases (counts per minute per liter): $\mathrm{C}_{1}=\mathrm{F}_{1} \lambda$ in well ventilated alveoli, $\mathrm{C}_{2}=\mathrm{F}_{2} \lambda$ in poorly ventilated alveoli; $\mathrm{C}_{\mathrm{a}}$ in arterial blood; $\mathrm{C}_{\bar{v}}$ in mixed venous blood and tissue. $\mathrm{C}_{\overline{\mathrm{v}}}{ }^{\prime}$ in mixed venous blood during passage in injectate. Solubility coefficient at body temperature: $\lambda$. Time (minutes) $: \mathrm{t}=$ time in general, $\mathrm{u}=$ time spent by blood in alveolar capillary; $t_{p}=$ time of maximal concentration in mixed venous blood. The symbol (0) signifies boundary conditions at zero time.

With these assumptions and symbols in mind, the behavior of the analog model can be expressed in the following way.

\section{Algebraic formulation}

1. Rate of change of krypton concentration: differential equations. Considering compartment $\mathrm{L}_{1}$ as an example, the following relationship holds for each instant:

$$
\frac{\mathrm{dX}}{\mathrm{dt}}=\frac{\mathrm{d}\left(\mathrm{L}_{1} \mathrm{~F}_{1}\right)}{\mathrm{dt}}=\left(\dot{\mathrm{Q}}_{1} \mathrm{C}_{\overline{\mathrm{v}}}+\dot{\mathrm{V}}_{1} 0\right)-\left(\dot{\mathrm{Q}}_{1} \mathrm{~F}_{1} \lambda+\mathrm{V}_{1} \mathrm{~F}_{1}\right) .
$$

Rearranging and using rate constants in Figure 1B, Equation 1 and the similar equations for $\mathrm{L}_{2}$ and $\mathrm{T}$ become:

$$
\begin{gathered}
\frac{\mathrm{dF}_{1}}{\mathrm{dt}}=\frac{\dot{Q}_{1}}{\mathrm{~L}_{1}} \mathrm{C}_{\overline{\mathrm{v}}}-\frac{\dot{\mathrm{Q}}_{1} \lambda}{\mathrm{L}_{1}} \mathrm{~F}_{1}-\frac{\dot{\mathrm{V}}_{1}}{\mathrm{~L}_{1}} \mathrm{~F}_{1} \\
\frac{\mathrm{dF}_{2}}{\mathrm{dt}}=\frac{\dot{Q}_{2}}{\mathrm{~L}_{2}} \mathrm{C}_{\overrightarrow{\mathrm{v}}}-\frac{\dot{\mathrm{Q}}_{2} \lambda}{\mathrm{L}_{2}} \mathrm{~F}_{2}-\frac{\dot{\mathrm{V}}_{2}}{\mathrm{~L}_{1}} \mathrm{~F}_{2} \\
\frac{\mathrm{dC}_{\overline{\mathrm{v}}}}{\mathrm{dt}}=\frac{\dot{\mathrm{Q}}_{1} \lambda}{\mathrm{T}} \mathrm{F}_{1}+\frac{\dot{\mathrm{Q}}_{2} \lambda}{\mathrm{T}} \mathrm{F}_{2}-\frac{\dot{\mathrm{Q}}_{1}}{\mathrm{~T}} \mathrm{C}_{\overline{\mathrm{v}}}-\frac{\dot{\mathrm{Q}}_{2}}{\mathrm{~T}} \mathrm{C}_{\overline{\mathrm{v}}}
\end{gathered}
$$

This system of three simultaneous linear differential equations, each being homogeneous, of the first order, and 
with constant coefficients, can be solved by classical methods to vield a solution in the following form (17):

$$
\begin{aligned}
& \mathrm{F}_{1}={ }^{1} \mathrm{C}_{1} \mathrm{e}^{\mathrm{m}_{1} t}+{ }^{1} \mathrm{C}_{2} \mathrm{e}^{\mathrm{m}_{2} t}+{ }^{1} \mathrm{C}_{3} \mathrm{e}^{\mathrm{m}_{3} t} \\
& \mathrm{~F}_{2}={ }^{2} \mathrm{C}_{1} \mathrm{e}^{\mathrm{m}_{1} t}+{ }^{2} \mathrm{C}_{3} \mathrm{e}^{\mathrm{m}_{2} t}+{ }^{2} \mathrm{C}_{3} \mathrm{e}^{\mathrm{m}_{3} t} \\
& \mathrm{C}_{\mathrm{v}}={ }^{3} \mathrm{C}_{1} \mathrm{e}^{\mathrm{m}_{1} \mathrm{t}}+{ }^{3} \mathrm{C}_{2} \mathrm{e}^{\mathrm{m}_{2} t}+{ }^{3} \mathrm{C}_{3} \mathrm{e}^{\mathrm{m}_{3} \mathrm{t}} .
\end{aligned}
$$

The exponents $m_{1}, m_{2}, m_{3}$ are the three roots of a cubic equation and can all be computed (e.g., by Newton's method) from the numerical values of $\dot{V}_{1}, \dot{V}_{2}, \dot{Q}_{1}, \dot{Q}_{2}, L_{1}$, $\mathrm{L}_{2}, \mathrm{~T}$ and $\lambda$. To determine the values of the constants (C's) in Equations 5, 6 and 7, it is necessary to know also the initial values $F_{1}(0), F_{2}(0)$ and $C_{\bar{v}}(0)$ of the krypton concentrations in the three compartments.

2. Initial krypton concentrations: boundary conditions, $F_{1}(0), F_{2}(0)$. These were determined by the following approach. It is assumed that the injectate reaches the lungs as a homogeneous square front slug which takes u minutes to pass through the alveoli. The value of $u$ was taken to be 0.2 minute. Its exact value has no important effect on our conclusions.

During this time the mixed venous concentration of krypton is constant at $\mathrm{C}_{\bar{v}^{\prime}}$, the prime indicating that we are dealing with the period during which boundary conditions are established.

Before the end of the passage of the injectate through the lungs, the tissue concentration of $\mathrm{Kr}^{85}\left(\mathrm{C}_{\bar{v}}\right)$ will have begun to rise. However, this rise is very small and it greatly simplifies the situation to regard it as negligible. In that case $C_{\bar{r}}(0)=0$, after the passage of the injectate through the lungs.

The equations which apply during the passage of the injectate through the lungs are the same as Equations 2, 3 and 4 , except that the variable $C_{\bar{v}}$ (from tissues) is replaced in all three equations by the constant $\mathrm{C}_{\bar{v}^{\prime}}$ (from injectate), so that Equation 4 becomes $\mathrm{dC}_{\overline{\mathrm{v}}^{\prime}} / \mathrm{dt}=0$

During the time $u, F_{1}$ and $F_{2}$ rise from zero to $F_{1}(u)$ and $F_{2}(u)$ at the end of the passage of the injectate through the lungs. By integration of Equations 2 and 3 under these conditions one has:

$$
F_{j}(u)=\frac{\dot{Q}_{j} C_{\bar{v}^{\prime}}^{\prime}}{\dot{V}_{j}+\dot{Q}_{j} \lambda}\left[1-\mathrm{e}^{-u\left(\dot{V}_{j}+\dot{Q}_{j} \lambda\right) / L_{j}}\right]
$$

where the subscript $\mathrm{j}$ is either 1 or 2 . These concentrations $\mathrm{F}_{1}(\mathrm{u})$ and $\mathrm{F}_{2}(\mathrm{u})$ occurring at the end of the passage of the slug are the peak values of $F_{1}$ and $F_{2}$, and are used as boundary conditions $\mathrm{F}_{1}(0)$ and $\mathrm{F}_{2}(0)$ in numerical examples discussed subsequently. The initial concentration in the tissues $\mathrm{C}_{\overline{\mathrm{v}}}(0)$ is zero.

It is relevant to our later discussion of the slow krypton method to consider what fraction $(\theta)$ of the krypton brought to the alveoli in the blood is lost in the expired gas and the blood which leaves during the passage of the injectate. The krypton remaining in the alveoli at the end of the passage of the injectate is $1-\theta$.

$$
\theta_{j}=\frac{\dot{Q}_{j} \mathrm{C}_{\bar{v}^{\prime} \mathrm{u}}-\mathrm{F}_{\mathrm{j}}(\mathrm{u}) \mathrm{L}_{\mathrm{j}}}{\dot{Q}_{\mathrm{j}} \mathrm{C}_{\overline{\mathrm{v}}^{\prime} \mathrm{u}}}=1-\frac{1-\mathrm{e}^{-\mathrm{u}\left(\dot{\mathrm{v}}_{\mathrm{j}}+\dot{\mathrm{Q}}_{\mathrm{j}} \lambda\right) / \mathrm{L}_{\mathrm{j}}}}{\mathrm{u}\left(\dot{\mathrm{V}}_{\mathrm{j}}+\dot{\mathrm{Q}}_{\mathrm{j}} \lambda\right) / \mathrm{L}_{\mathrm{j}}}
$$

in which $\dot{Q}_{j} \mathrm{C}_{\bar{r}}^{\prime} \mathrm{u}$ is the quantity of $\mathrm{Kr}^{85}$ brought to these alveoli by the blood, and $F_{j}(u)=F_{j}(0)$. Figure 2 illustrates the values of $\theta$ for alveoli of different quantities of

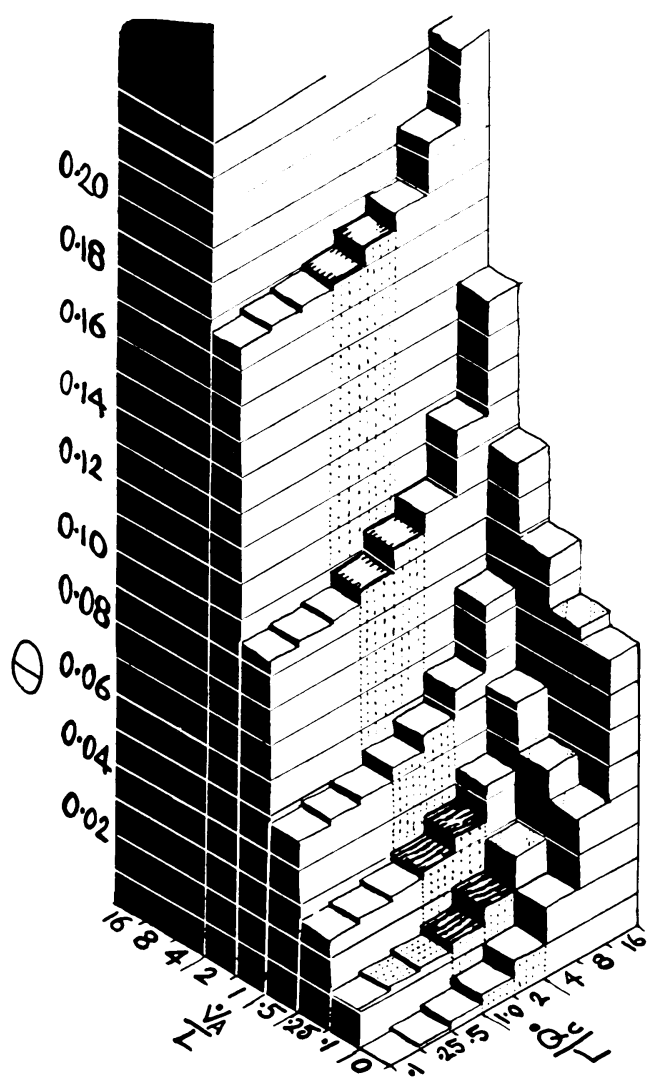

Fig. 2. The RELATION BETWEex ALVEOLAR VENTILATION, ALVECIAR PERFESION, LCNG VOLLME AND THE FRACTION OF THE INJECTED KRY PTON REMAINING IN THE ALVEOLI AFTER PASSAGE THROLGH THE LCNG OF THE INJECTATE, $\theta$ is the fraction of the injected $\mathrm{Kr}^{85}$ which is lost from the alveoli in expired gas and end capillary blood during the passage of the injectate. This passage occupies time u, which is 0.2 minute in this case. The diagram shows how much $\theta$ changes with variation in blood perfusion per unit lung volume $\left(\dot{Q}_{c} / L\right)$ and alveolar ventilation per unit lung volume $\left(\dot{V}_{A} / L\right)$. The four blocks whose tops are shaded apply to conditions in $L_{2}$ and indicate that in this case $\theta$ $=1$ to 3 per cent.

ventilation and perfusion per unit lung volume. In the case of the "slow" alveoli, $\theta$ is about 0.02. This concludes the discussion of the boundary conditions.

When I, $\dot{Q}_{1}, \dot{Q}_{2}, L_{1}, L_{2}, \dot{V}_{1}, \dot{V}_{2}$, T and u are known, then $F_{1}(0)$ and $F_{2}(0)$ can be determined.

3. Krypton concentrations resulting from admixture: mixing equations. Mixed expired alveolar gas is formed by admixture from $L_{1}$ and $L_{2}$ and its krypton concentration is:

$$
\mathrm{F}_{\mathrm{A}}^{\mathrm{e}}=\frac{\dot{\mathrm{V}}_{1} \mathrm{~F}_{1}+\dot{\mathrm{V}}_{2} \mathrm{~F}_{2}}{\dot{\mathrm{V}}_{1}+\dot{\mathrm{V}}_{2}} .
$$

Arterial blood is also formed by admixture,

$$
\mathrm{Ca}=\frac{\dot{Q}_{1} \lambda F_{1}+\dot{Q}_{2} \lambda F_{2}}{\dot{Q}_{1}+\dot{Q}_{2}}
$$


TABLE I

Parameters and boundary conditions used for the calculation of the three numerical examples*

\begin{tabular}{|c|c|c|c|c|c|}
\hline Numerical example & I & II & & IIIa & IIIb \\
\hline $\begin{array}{ll}\text { Lung space } & \mathrm{L}_{1} \\
\text { (liters) } & \mathrm{L}_{2}\end{array}$ & $\begin{array}{l}1 \\
4\end{array}$ & $\begin{array}{l}1 \\
4\end{array}$ & & $\begin{array}{l}1 \\
4\end{array}$ & $\begin{array}{l}1 \\
4\end{array}$ \\
\hline $\begin{array}{l}\text { Tissue space } \frac{T}{\dot{V}_{1}} \\
\text { Ventilation } \\
(L / \text { min })\end{array}$ & $\begin{array}{l}60 \\
4.5 \\
0.5\end{array}$ & $\begin{array}{r}10 \\
4.5 \\
0.5\end{array}$ & & $\begin{array}{r}60 \\
4.5 \\
0.5\end{array}$ & $\begin{array}{l}60 \\
4.5 \\
0.5\end{array}$ \\
\hline $\begin{array}{ll}\text { Perfusion } & \dot{Q}_{1} \\
(L / \text { min }) & \dot{Q}_{2}\end{array}$ & $\begin{array}{l}2 \\
3\end{array}$ & $\begin{array}{l}2 \\
3\end{array}$ & & $\begin{array}{l}1.4 \\
3.6\end{array}$ & $\begin{array}{l}1.4 \\
3.6\end{array}$ \\
\hline $\begin{array}{l}\mathrm{F}_{1}(0)(c p m / L) \\
\mathrm{F}_{2}(0) \\
\mathrm{C}_{\mathrm{v}}^{-}(0)\end{array}$ & $\begin{array}{c}131,000 \\
74.000 \\
0\end{array}$ & $\begin{array}{c}131,000 \\
74,000 \\
0\end{array}$ & \multicolumn{3}{|c|}{ 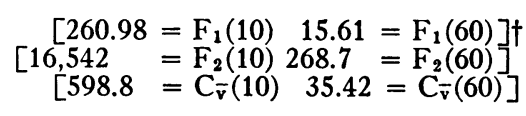 } \\
\hline $\begin{array}{l}\text { Amount of } \mathrm{Kr}^{85} \\
\text { injected at zero } \\
\text { minus } \mathrm{u}(=0.2) \mathrm{min} \\
(c p m)\end{array}$ & & 500,000 & & & \\
\hline
\end{tabular}

* The parameters are assumed round figures which are typical of patients with severe chronic pulmonary emphysema. The boundary conditions have been calculated from the amount of $\mathrm{Kr}^{85}$ injected (I $=500,000$ counts per minute), its passage time, $u$, through the pulmonary capillaries $(u=0.2 \mathrm{~min})$, and the parameters for examples I and II.

$\dagger$ In examples IIIa and IIIb the boundary conditions are concentrations, respectively, 10 or 60 minutes after injection. These are indicated by the symbols $F_{1}(10), F_{2}(10), C_{\bar{v}}(10)$, and $F_{1}(60), F_{2}(60), C_{\bar{v}}(60)$.

Thus the behavior of the analog model, i.e., the changes with time of the $\mathrm{Kr}^{85}$ concentrations in the three mixing chambers, in arterial blood and in mixed expired alveolar gas can be completely described in terms of its parameters (size of chambers, exchange rates of carrier between chambers) and the boundary conditions. Mixed expired gas is mixed expired alveolar gas diluted by the admixture of dead space ventilation. Therefore, the mixed expired krypton concentration is:

$$
F_{E}=F_{A}^{e} \frac{\dot{V}_{1}+\dot{V}_{2}}{\dot{V}_{1}+\dot{V}_{2}+\dot{V}_{D}}
$$

where $\dot{\mathrm{V}}_{1}+\dot{\mathrm{V}}_{2}+\dot{\mathrm{V}}_{\mathrm{D}}=\dot{\mathrm{V}}_{\mathrm{E}}$. $\quad \dot{\mathrm{V}}_{\mathrm{D}}$ is constant in any study and must be determined by other methods (18).

\section{Numerical examples calculated from the analog model}

Three numerical examples have been calculated in detail. 1. It was of interest to know how the model behaves if the naturally occurring situation is imitated as closely as possible. The values chosen for the parameters $L_{1,2}, \dot{V}_{1,2}$ and $\dot{Q}_{1,2}$ are typical of those found by other methods in patients with severe chronic pulmonary emphysema (6). These parameters are listed in Table I, (numerical examples I and II).

2. The volume of tissues, however, which equilibrates with $\mathrm{Kr}^{85}$ in such patients is not known, even as an approximation. An attempt was, therefore, made to assess the magnitude of the possible effect of the tissue volume on the washout of $\mathrm{Kr}^{85}$ by considering two extreme situations :

TABLE II

Numerical values of the exponents, $m$, and the constants of integration, $C$, of Equations 6,7 and 8 calculated from the figures listed in Table $I^{*}$

\begin{tabular}{ccccc}
\hline Numerical example & I & II & IIIa & IIIb \\
\hline $\mathrm{m}_{1}$ & -4.6007 & -4.6049 & -4.5703 \\
$\mathrm{~m}_{2}$ & -0.1814 & -0.5260 & -0.1943 \\
$\mathrm{~m}_{3}$ & -0.0636 & -0.1315 & -0.0586 \\
${ }^{1} \mathrm{C}_{1}$ & $130,996.7$ & $130,960.0$ & 77.215 & 4.5823 \\
${ }^{1} \mathrm{C}_{2}$ & -706.90 & $-1,232.488$ & -83.013 & 0.1307 \\
${ }^{1} \mathrm{C}_{3}$ & 709.868 & $1,272.158$ & 266.777 & 10.8969 \\
${ }^{2} C_{1}$ & 8.157 & 54.168 & 0.0040 & 0.00024 \\
${ }^{2} C_{2}$ & $61,777.3$ & $5,180.114$ & -15.1144 \\
${ }^{2} C_{3}$ & $12,214.4$ & $68,765.82$ & $6,948.32$ & 283.814 \\
${ }^{3} C_{1}$ & -48.273 & -320.85 & -0.019 & -0.00117 \\
${ }^{3} C_{2}$ & $-1,561.73$ & $-2,510.58$ & -259.455 & 0.4087 \\
${ }^{3} C_{3}$ & $1,610.11$ & $2,842.32$ & 859.66 & 35.114
\end{tabular}

* The units of the constants are counts per minute per liter, and of the exponents, minutes ${ }^{-1}$. 
in one numerical example (no. I) a value of $60 \mathrm{~L}$ was arbitrarily chosen for the tissue volume $T$, whereas in the second numerical example (no. II) $\mathrm{T}$ was assumed to be $10 \mathrm{~L}$ (see Table I).

3. It has been shown that the blood flow supplying the poorly ventilated lung space in emphysematous subjects increases by about 20 per cent when 100 per cent $\mathrm{O}_{2}$ is breathed instead of room air (7). In order to confirm this finding, a number of studies was made in which the patient was switched from room air to pure oxygen as the inspired gas in the middle of a $\mathrm{Kr}^{85}$ washout. It was expected that a 20 per cent change in the distribution of perfusion to the

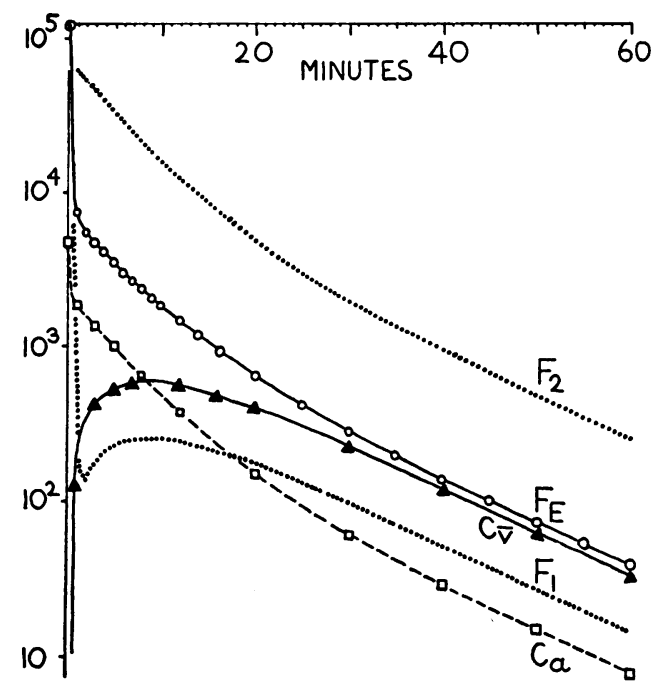

Fig. 3. THE WASHOUT OF KRYPTON FROM THE MODEL IN EXAMPLE I WiTh TISSUE volume (T) $60 \mathrm{~L}$. Symbols are the same in Figures 3 through 7. Circles, expired airconcentration, $\left(\mathrm{F}_{E}\right)$; squares, arterial blood concentration, $\left(C_{\mathrm{a}}\right)$; triangles, mixed venous blood, $\left(\mathrm{C}_{\overline{\mathrm{v}}}\right)$. In Figures 3 and 4 the krypton concentration in the well ventilated $\left(F_{1}\right)$ and poorly ventilated $\left(F_{2}\right)$ alveoli are indicated by dotted lines. Ordinates in Figures 3, 4 and 5 are counts per minute per liter on a logarithmic scale. In these same figures the dead space ventilation $\left(\dot{V}_{D}\right)$ is assumed to be zero, so that $F_{E}=F_{A^{\circ}}$. When dead space ventilation is not zero all values of $F_{E}$ are reduced: $F_{E}=F_{A}{ }^{e}\left(\dot{V}_{E}-\dot{V}_{D}\right) /$ $\dot{\mathrm{V}}_{\mathrm{E}}$, and would lie in a line below but parallel to the $\mathrm{F}_{\mathrm{E}}$ lines in Figures 3, 4 and 5. The curves for $F_{1}, F_{2}, C_{8}, C_{\bar{v}}$ are not affected by the magnitude of the dead space ventilation.

lung would be reflected in a detectable alteration of the washout pattern. In the numerical exampie III, we study this in the analog model by assuming that an instantaneous 20 per cent increase of $\dot{Q}_{2} / \dot{Q}_{\mathrm{T}}$ occurs 10 minutes (example IIIa) and 1 hour (example IIIb), respectively, after the injection of $\mathrm{Kr}^{85}$. The parameters which apply to this situation are again listed in Table I (numerical examples IIIa and IIIb). Using the figures listed in Table I the numerical values for the constants of integration and the

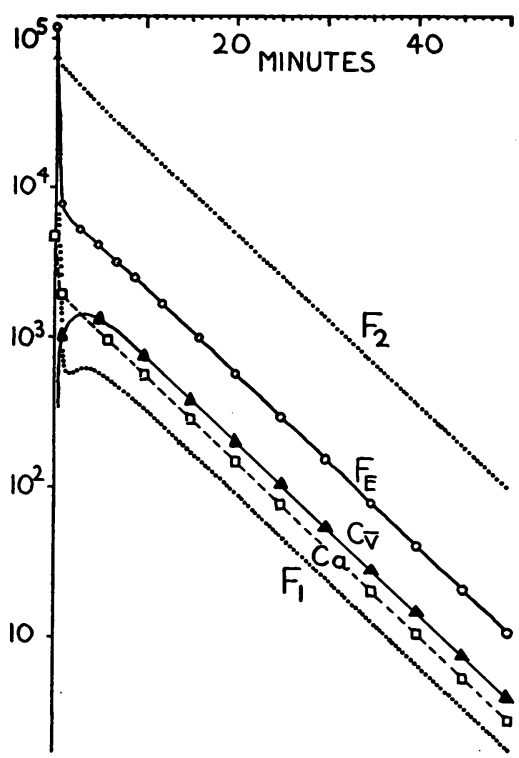

Fig. 4. WAShOUT OF $\mathrm{KR}^{85}$ FROM THE MODEL IN EXAMple II, with tissue volume (T) $10 \mathrm{~L}$. The venous peak is earlier than in Figure 1 and compares with Figures 5 and 6.

exponents $m_{1}, m_{2}$ and $m_{3}$ of Equations 5, 6 and 7 have been computed (Table II). Finally, the values of $F_{1}, F_{2}, C_{\bar{v}}$, $\mathrm{F}_{\mathrm{A}} \mathrm{e}$, and $\mathrm{C}_{\mathrm{a}}$ have been computed for times varying from 0 to 120 minutes after injection. The corresponding curves are shown in Figures 3, 4 and 5.

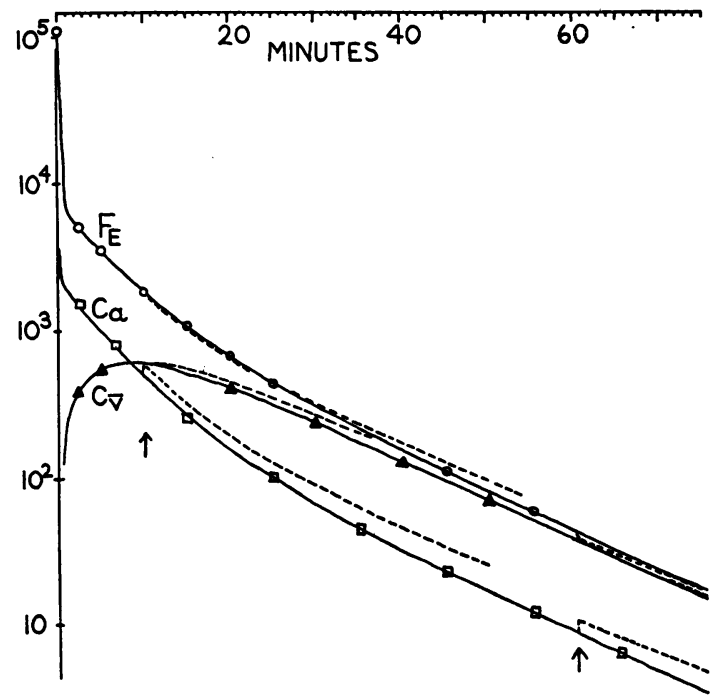

Fig. 5. WASHOUT OF $\mathrm{KR}^{85}$ IN THE MODEL III IN WHICH THE DISTRIBUTION OF PERFUSION CHANGES ABRUPTLY AT 10 MiNUTES (IIIA) OR AT 60 MINUTES (B). The modified curves of $F_{E}, C_{a}$ and $C_{\bar{v}}$ resulting from this are indicated by dashed lines. The main effect of this change in the distribution of perfusion is on $C_{\mathrm{a}}$. 


\section{COMPARISON OF THEORETICAL AND EXPERIMENTAL, CURVES}

\section{A. Theoretical curves}

As can be seen in Figures 3 and 4, both mixed expired air and mixed arterial blood behave similarly up to about 15 minutes. Thereafter, however, the washout in example I becomes much more delayed; this is due to the large size of the tissue compartment. The concentration of $\mathrm{Kr}^{85}$ is highest at all times, except the first few seconds in the poorly ventilated alveoli $\left(\mathrm{L}_{2}\right)$. In the first few seconds the concentration in the well ventilated alveoli $\left(F_{1}\right)$ may exceed this if its blood flow $\left(\dot{Q}_{1}\right)$ is large in relation to its volume $\left(L_{1}\right)$. $F_{1}$ falls steeply due to its large relative ventilation $\left(\dot{\mathrm{V}}_{1} / \mathrm{L}_{1}\right)$ and then rises at about two minutes when $\mathrm{Kr}^{85}$ returns in larger amounts from the tissues $\left(\mathrm{C}_{\overline{\mathrm{v}}}\right)$. However, these events in $\mathrm{F}_{1}$ occur at insignificant concentrations, and concern insignificant amounts of $\mathrm{Kr}^{85}$, when compared to the much larger concentrations and quantities of $\mathrm{Kr}^{85}$ in other chambers at the same time.

$\mathrm{F}_{\mathrm{E}}$ always exceeds $\mathrm{C}_{\mathrm{a}}$; in Figures 3 and 4 these lines run approximately parallel courses. Both these parameters are formed by admixture, so $F_{E}$ must always lie between $F_{1}$ and $F_{2}$, and $C_{a}$ between $\mathrm{C}_{1}$ and $\mathrm{C}_{2}$.

The venous and tissue concentration $\left(\mathrm{C}_{\overline{\mathrm{v}}}\right)$ is initially zero and rises rapidly to a peak. It then falls gradually back toward zero. The quantity of $\mathrm{Kr}^{85}$ entering the tissues before the peak is equal to the total quantity leaving the tissues after the peak, i.e., $\dot{\mathrm{Q}}_{\mathrm{T}} \int_{0}^{t_{\mathrm{p}}}\left(\mathrm{C}_{\mathrm{a}}-\mathrm{C}_{\overline{\mathrm{v}}}\right) \cdot \mathrm{dt}$ $=\dot{Q}_{\mathrm{T}} \int_{t_{p}}^{\infty}\left(C_{\bar{v}}-C_{a}\right) \cdot d t$, where $t_{p}$ is the time of the peak, or more generally: $\int_{0}^{\infty}\left(C_{a}-C_{\bar{v}}\right)$ $\cdot d t=0$. The peak of venous concentration occurs at the crossover point where $\mathrm{C}_{\mathrm{a}}=\mathrm{C}_{\overline{\mathrm{v}}}$. The time at which this peak occurs depends on the tissue volume; it is earlier in example II with the small tissue volume.

In example I, with a large tissue volume, this dominates the rate of the latter stages of washout. $\mathrm{C}_{\overline{\mathrm{v}}}$ exceeds $\mathrm{C}_{\mathrm{a}}$ by much more than it does in example II. There is an inflection in the lines in example I after 20 minutes which is not seen in example II. $F_{1}$ exceeds $C_{a}$ in example $I$ but not in example II, due to this cause. The partial pressure in the tissues exceeds that in $\mathrm{L}_{2}$ by a considerable amount in the late stages of example I, but not in example II. (Equal partial pressures occur in Figures 3, 4 and 5 when $F_{2}=20$ $\mathrm{C}_{\mathrm{v}}$ )

\section{B. Experimental curves}

It is instructive to consider the situation which is found to occur in fact when $\mathrm{Kr}^{85}$ is injected into patients with emphysema.

Most of the experimental data which have been obtained so far were based on curves of $\mathrm{Kr}^{85}$ decay in expired air and arterial blood after injection of $300 \mu \mathrm{c}(7)$. A few studies are available, however, with the more complete protocol which included mixed venous blood. Examples are given in Figures 6 and 7 which should be compared with Figures 3 and 4 . In Case I, 1,000 $\mu \mathrm{c}$ of $\mathrm{Kr}^{85}$ was injected through a cardiac catheter into the pulmonary artery. ${ }^{1}$ Another cardiac catheter was used to sample venous blood. This catheter was in the superior vena cava. In Case II, $600 \mu \mathrm{c}$ of $\mathrm{Kr}^{85}$ was injected into the right ventricle through one catheter, while the other catheter sampled mixed venous blood in the right atrium. Samples were taken at the times indicated in Figures 6 and 7 from the brachial artery and from collections of mixed expired air, as well as from the cardiac catheter. The two subjects (Figures 6 and 7) resemble the model example $I$ in the approximately parallel course taken by $C_{a}$ and $F_{E}$. The wider separation of these in the subjects is due to the higher counting efficiency of our equipment for gases, which is not allowed for in the model curves. They also resemble the model in the times at which the various exponents dominate the $F_{E}$ curve. The first rapid exponent has no apparent effect after about 5 minutes. The third exponent does not dominate until after 20 minutes have elapsed.

Subject I (Figure 6) shows resemblance both to example I (Figure 4) and example II (Figure 5). As in example I, he has a prolonged slow washout, presumably from tissues, which indi-

1 The tracheal mucosa, which is the tissue most irradiated, receives a dose of $0.7 \mathrm{rad}$ after the intravenous injection of $1,000 \mu \mathrm{c}$ of $\mathrm{Kr}^{85}$. This small dose is calculated on the basis of a biological half-life of 10 minutes. 
cates that some tissues which took up $\mathrm{Kr}^{85}$ are perfused by a relatively small blood flow. Like example II, he shows an early venous concentration peak, but this peak does not coincide with the crossover point of the arterial and venous concentration curves. When mixed venous blood is sampled, it is mathematically inevitable that the peak coincides with the crossover point. The inconsistency here arises from the position of the sampling catheter in the superior vena cava. Case II is given here, although the smaller injected dose results in low and therefore

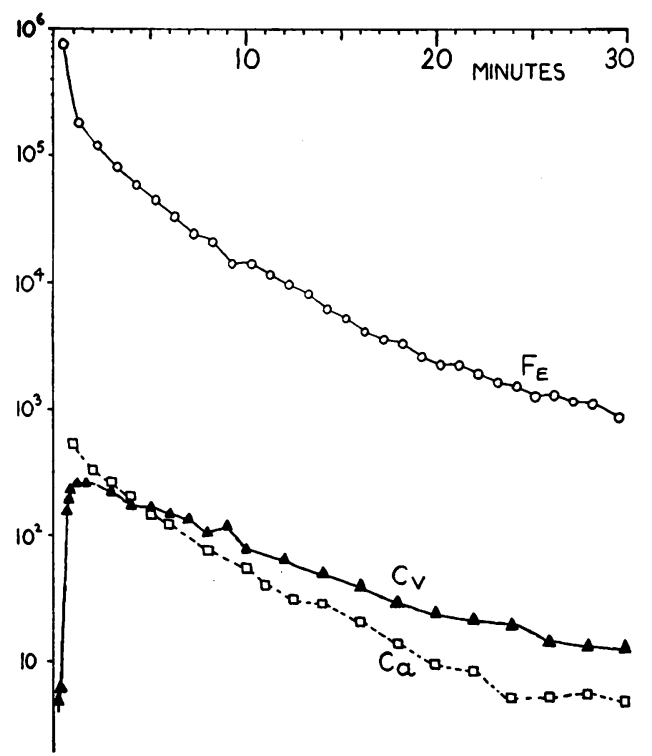

Fig. 6. Washout of $\mathrm{KR}^{85}$ in CASE I, With CHRONIC PULMONARY EMPHYSEMA. The venous sampling catheter was in the superior vena cava. The venous peak is at 2 minutes. The $\mathrm{C}_{\mathrm{a}}$ and $\mathrm{C}_{\overline{\mathrm{v}}}$ lines cross later (see text). In Figures 6 and 7 the ordinates are counts per minute on a logarithmic scale. In blood, $1 \mathrm{~m} \mu \mathrm{c}$ per $\mathrm{ml}$ gives $70 \mathrm{cpm}$; in gas, $1 \mathrm{~m} \mu \mathrm{c}$ per $\mathrm{ml}$ gives $6,200 \mathrm{cpm}$.

erratic counts later in the study, to show that when mixed venous blood is sampled inside the heart, the peak and crossover points do in fact coincide. Furthermore, the peak occurs early, as in example II, rather than late, as in example I.

These considerations suggest that when dealing with the earlier points of the curve ( 0 to 15 minutes), the model with the small effective tissue volume (example II) is more applicable, whereas in the late stages (60 minutes), the model with the large tissue volume (example I)

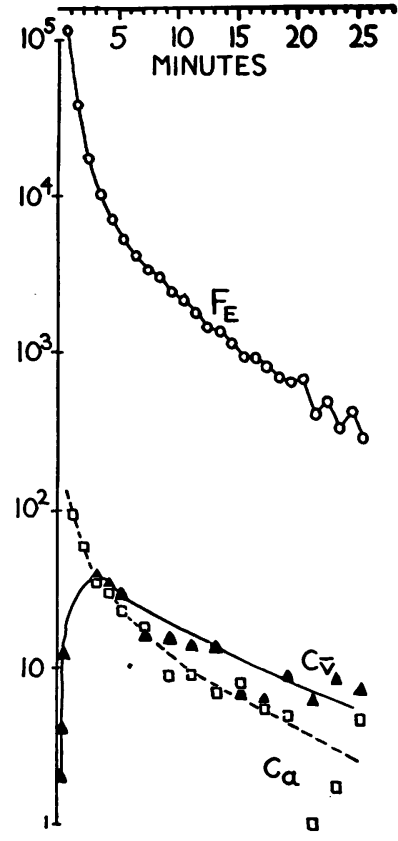

Fig. 7. Washout of $\mathrm{KR}^{85}$ in CASE II With Chronic PULMONARY EMPHYSEMA. The venous peak is at 3 minutes and coincides with the crossover point of the $\mathrm{C}_{\mathrm{a}}$ and $\mathrm{C}_{\overline{\mathrm{v}}}$ lines. The venous sampling catheter was in the right auricle. The later $C_{a}$ and $C_{\bar{v}}$ points are scattered because of the low activity after a relatively small injectate (see text).

is closer to the observed facts. At least two tissue compartments with different blood flows per unit volume would be needed to fit an early peak which occurred with a slow rate of late fall in $\mathrm{C}_{\overline{\mathrm{v}}}$ as is suggested by the lines drawn among the scattered points in Figure 7.

TABLE III

Effects of changes in the distribution of perfusion upon the ratio of $K r^{85}$ concentration between arterial blood $\left(C_{a}\right)$ and the expired air $\left(F_{E}\right)^{*}$

\begin{tabular}{|c|c|c|c|}
\hline \multirow{2}{*}{$\begin{array}{c}\text { Time } \\
\text { after } \\
\text { injection }\end{array}$} & \multirow{2}{*}{$\frac{\begin{array}{c}\dot{Q}_{2} / \dot{Q}_{\mathrm{T}} \\
\text { unchanged }\end{array}}{\mathrm{C}_{\mathrm{s}} / \mathrm{F}_{\mathrm{E}}}$} & \multicolumn{2}{|c|}{$\begin{array}{c}\dot{Q}_{2} / \dot{Q}_{\mathrm{T}} \text { increased } \\
\text { by } 20 \%\end{array}$} \\
\hline & & $\mathrm{C}_{\mathrm{a}} / \mathrm{F}_{\mathrm{E}}$ & Increase \\
\hline $\min$ & & A† & $\%$ \\
\hline 10 & 0.265 & 0.318 & 20 \\
\hline 12 & 0.258 & 0.320 & 24 \\
\hline 50 & 0.205 & 0.273 & 33 \\
\hline & & $\mathrm{B} \dagger$ & \\
\hline 60 & 0.204 & 0.241 & 18 \\
\hline 62 & 0.204 & 0.268 & 31 \\
\hline 100 & 0.204 & 0.273 & 34 \\
\hline
\end{tabular}

* Dead space ventilation is zero, so $\mathrm{F}_{\mathrm{E}}=\mathrm{F}_{\mathrm{A}}{ }^{\circ}$.

$\dagger \mathrm{A}$, at 10 minutes; $\mathrm{B}$, at 60 minutes. 
Be that as it may, the data in Figures 6 and 7 show reasonable agreement with the threecompartment model and the imperfections and irregularities inevitable in data of this type do not warrant any more involved system of interpretation at present.

\section{Influence of instantaneous changes in the distri- bution of perfusion upon the curves}

The principal changes occurring in the washout pattern when the distribution of perfusion is altered instantaneously (increase of $\dot{Q}_{2} / \dot{Q}_{\mathrm{T}}$ by 20 per cent) are summarized in Table III. The most striking change takes place in the mixed arterial blood : its $\mathrm{Kr}^{85}$ concentration increases instantaneously by 20 per cent if the distribution of perfusion changes at 10 minutes and by 18 per cent if $\dot{Q}_{2} / \dot{Q}_{\mathrm{T}}$ rises at 60 minutes. An equally important change will occur in the ratio of the $\mathrm{Kr}^{85}$ concentrations of simultaneously collected arterial blood and gas specimens. However, the changes in the $F_{E}$ and $C_{\bar{v}}$ curves are slight, as can be seen in Figure 5. This illustrates the important point that changes in the distribution of perfusion can be detected only by the arterial blood composition, or by some ratio related to this, such as $\mathrm{C}_{\mathrm{a}} / \mathrm{F}_{\mathrm{E}}$.

IV. METHODS FOR THE ANALYSIS OF EXPERIMENTAL CURVES TO DERIVE RELATIVE VENTI-

LATION AND/OR PERFUSION OF COMPARTMENTS

So far we have been considering the behavior of a theoretical three-compartment model. We have chosen arbitrary values for its parameters and tried to predict the changes with time of $\mathrm{Kr}^{85}$ in the three compartments. The ultimate aim of a washout study is, of course, reciprocal: we must analyze the experimental data and we want to determine from such an analysis as many parameters as possible (i.e., in our case, volumes, ventilation and perfusion).

Such an analysis will vary depending on whether the experimental protocol provides access to all three possible sampling sites-expired air, arterial and mixed venous blood (which entails sampling from the right heart) - or whether access is limited to expired air and arterial blood. First, a method is indicated which might be used under optimal conditions. Second, two approximation methods are described which have been widely used for the evaluation of actual experimental data. Finally, an attempt is made to assess the possible error introduced by the use of approximation formulae.

\section{A. Exact analysis for curves obtained under opti- mal conditions: sampling from three sites- $C_{\bar{v}}, C_{a}$ and $F_{E}$}

The task in this case is to analyze the three experimental curves for $F_{E}, C_{a}$ and $C_{\bar{v}}$. Since the $C_{\bar{v}}$ curve represents the output from one single compartment, its conventional analysis (10) should readily yield the numerical values of its constants and exponents, i.e., ${ }^{3} \mathrm{C}_{1},{ }^{3} \mathrm{C}_{2},{ }^{3} \mathrm{C}_{3}$ and $\mathrm{m}_{1}, \mathrm{~m}_{2}$ and $\mathrm{m}_{3}$. This, however, can only yield useful values when the data show less scatter and continue for longer periods than is the case in Figures 6 and 7, since the first stage in the analysis is the exact determination of the slowest component of the washout in venous blood. The analysis of the $F_{E}$ and $C_{a}$ curves is complicated by the fact that they each represent a mixture of the contents of more than one compartment. Nevertheless, a method for deriving the values of $\dot{Q}_{1}, \dot{Q}_{2} . \dot{V}_{1}, \dot{V}_{2}, L_{1}, L_{2}$ and $T$ from the analysis of the curves has been developed. ${ }^{2}$ It would be very laborious to use in practice. Furthermore, the values derived are most sensitive to the rate of washout from the tissues, and are dependent on the assumption that there is only one tissue compartment.

\section{B. Sampling from two sites for a limited time $-C_{a}$ and $F_{E}$ : approximation methods}

If catheterization of the right heart cannot be performed, no representative specimen of mixed venous blood can be obtained and sampling is confined to mixed arterial blood and mixed expired air. Furthermore, in practice, studies are limited in time. When $300 \mu \mathrm{c}$, which was the usual dose, is injected $C_{a}$ and $F_{E}$ are too low for accurate counting with our equipment about 20 minutes after injection.

The slow krypton method for determining $\dot{Q}_{2} / \dot{Q}_{T}$. This depends on the notion that the fate of the injected $\mathrm{Kr}^{85}$ is determined in the branches of

\footnotetext{
${ }^{2} \mathrm{~A}$ description of this method of analysis, which was developed with the help of Mr. Boss, will be sent by the authors on request.
} 
the pulmonary artery a few seconds after injection, and just prior to its passage through the lung. Those $\mathrm{Kr}^{85}$ molecules which are directed to the well ventilated alveoli pass into the alveolar gas and are rapidly eliminated in the expired air in the next two or three minutes. Those molecules which are directed to the poorly ventilated alveoli remain much longer in alveolar gas. They are slowly eliminated in the expired air from the poorly ventilated alveoli and to a lesser extent from the well ventilated alveoli which they reach after transfer to and temporary storage in the tissues. An assessment of this quantity which is slowly eliminated is made as follows.

It can be seen from Figure 7 (experimental data) that, when data for $F_{E}$ are available for only 20 minutes they resemble, within the limits of experimental error, a washout with only two exponents, $\mathrm{m}_{4}$ and $\mathrm{m}_{6}$, and two constants, $\mathrm{C}_{4}$ and $\mathrm{C}_{5}$ :

$$
\mathrm{F}_{E}=\mathrm{C}_{4} \mathrm{e}^{\mathrm{m}_{4} \mathrm{t}}+\mathrm{C}_{5} \mathrm{e}^{\mathrm{m}_{5} \mathrm{t}} .
$$

The values for $m_{5}$ and $C_{5}$ can be determined by the slope and the intercept at zero time of a line drawn through the data between 5 and 20 minutes. These constants do not necessarily have any simple relationship to those numbered 1,2 and 3. There is no need for such algebraic formulation since they are used merely to derive an integral: $\dot{\mathrm{V}}_{E} \cdot \mathrm{C}_{5} \int_{0}^{\infty} \mathrm{e}^{\mathrm{m} s \mathrm{t}} \cdot \mathrm{dt}$. This quantity of krypton which is slowly eliminated is considered as an approximation to consist of those molecules which were present in $\mathrm{L}_{2}$ at zero time, i.e.,

$$
\mathrm{F}_{2}(0) \mathrm{L}_{2}=\dot{\mathrm{V}}_{\mathrm{E}} \mathrm{C}_{5} \int_{0}^{\infty} \mathrm{e}^{\mathrm{mst}} \cdot \mathrm{dt} .
$$

Furthermore, it is shown in Figure 2 that $\theta$ is about 2 per cent in the slow alveoli, i.e., 98 per cent of the $\mathrm{Kr}^{85}$ which reached these alveoli in the blood during the passage of the injectate is present in the alveolar gas at the end of this passage. Thus $\mathrm{L}_{2} \cdot \mathrm{F}_{2}(0)=\mathrm{I} \cdot \dot{\mathrm{Q}}_{2} / \dot{\mathrm{Q}}_{\mathrm{T}}$ where $\mathrm{I}$ is the total quantity of $\mathrm{Kr}$ injected. Therefore, $\dot{\mathrm{Q}}_{2} / \dot{\mathrm{Q}}_{\mathrm{T}}$ can be estimated by the relationship:

$$
\frac{\dot{\mathrm{Q}}_{2}}{\dot{\mathrm{Q}}_{\mathrm{T}}}=\frac{\dot{\mathrm{V}}_{\mathrm{E}} \mathrm{C}_{5} \int_{0}^{\infty} \mathrm{e}^{\mathrm{m} 5 \mathrm{t}} \cdot \mathrm{dt}}{\mathrm{I}}
$$

where I is the total quantity injected or the total quantity eliminated in expired gas in infinite time. This approximation was tested by analyzing the data over the period 5 to 20 minutes in examples I and II in each of which $\dot{Q}_{2} / \dot{Q}_{T}=$ 0.60. In example I, $\dot{Q}_{2} / \dot{Q}_{\mathrm{T}}$ was estimated at 0.524 , an error of -12.6 per cent. In example II the estimate was 0.609 , an error of +1.5 per cent.

The partition coefficient method for determining $\dot{Q}_{2} / \dot{Q}_{T}$. Like the slow krypton method, this method of assessing $\dot{Q}_{2} / \dot{Q}_{\mathrm{T}}$ depends on data collected in studies limited in time to 15 or $20 \mathrm{~min}$ utes. In this case data for both $\mathrm{C}_{\mathrm{a}}$ and $\mathrm{F}_{\mathrm{E}}$ are used. It is evident from study of examples I and II that in the period from between 5 and 20 minutes after injection, the $\mathrm{Kr}^{85}$ which was initially present in the fast alveoli, $L_{1} F_{1}(0)$, has been eliminated. The only $\mathrm{Kr}^{85}$ in $\mathrm{L}_{1}$ is that brought by the blood from the tissues. During this period $F_{1}$ is small compared to $F_{2}$, and may be regarded as negligible. If $F_{1}$ is zero then the only source of $\mathrm{Kr}^{85}$ in $\mathrm{C}_{\mathrm{a}}$ and $\mathrm{F}_{\mathrm{E}}$ in this period, from 5 to 20 minutes, is $L_{2}$. In that case the following approximate relationship can be used to determine $\dot{Q}_{2} / \dot{Q}_{\mathrm{T}}$ :

$$
\frac{\mathrm{F}_{\mathrm{E}}}{\mathrm{C}_{\mathrm{a}}}=\frac{\dot{\mathrm{V}}_{2}}{\dot{\mathrm{V}}_{\mathrm{E} \lambda}} \div \frac{\dot{\mathrm{Q}}_{2}}{\dot{\mathrm{Q}}_{\mathrm{T}}}
$$

in which $\mathrm{C}_{\mathrm{a}}$ and $\mathrm{F}_{\mathrm{E}}$ are simultaneous measurements at a time between 5 and 20 minutes after injection, and $\dot{\mathrm{V}}_{2} / \dot{\mathrm{V}}_{\mathrm{E}}$ is known by use of another technique ( $\mathrm{N}_{2}$ washout curve). Applying this method to examples I and II in which $\dot{\mathrm{Q}}_{2} / \dot{\mathrm{Q}}_{\mathrm{T}}$ $=0.60$ we have estimates of 0.543 and 0.524 for $\dot{\mathrm{Q}}_{2} / \dot{\mathrm{Q}}_{\mathrm{T}}$. They are in error by -9.5 and -12.6 per cent, respectively.

Thus, these two arbitrary assessments of $\dot{\mathrm{Q}}_{2} / \dot{\mathrm{Q}}_{\mathrm{T}}$, the slow krypton method and the partition coefficient method, have errors in these examples comparable to the errors of other physiological assessments in man.

\section{SUMMARY}

1. The behavior of intravenously injected $\mathrm{Kr}^{85}$ in the emphysematous patient is considered in terms of a model composed of three compartments: well ventilated alveoli, poorly ventilated alveoli, and tissues.

2. The differential equations applicable in 
this model have been solved. Using typical emphysematous values for the volume, ventilation and blood flows of the two lung compartments, the behavior of $\mathrm{Kr}^{85}$ in the various gases and blood streams is predicted when the effective tissue volume is either 10 or $60 \mathrm{~L}$. Further calculated examples show the predicted effect of changes, during a study, in the distribution of blood flow to the lungs.

3. Data are presented on the findings in two patients with emphysema in whom $\mathrm{Kr}^{85}$ concentrations were followed in expired air, arterial blood and mixed venous blood, after intracardiac injection of $\mathrm{Kr}^{85}$. The behavior of the patients resembled that predicted for the model; the differences are discussed.

4. A method has been developed in which, by analysis of simultaneous expired, arterial and mixed venous concentration curves, the distribution of perfusion to the lung could be assessed. It is laborious in use and of very doubtful validity. Two approximate methods for determining the distribution of perfusion in the lung are presented. One depends only on expired gas analysis and the other on expired gas and arterial blood analysis. When tested on the predicted curves these appear to be in error by about 10 per cent.

\section{ACKNOWLEDGMENT}

The authors are indebted to Dr. Domingo Gomez for help and instruction in the mathematics used.

\section{REFERENCES}

1. Robertson, J. S., Siri, W. E., and Jones, H. B. Lung ventilation patterns determined by analysis of nitrogen elimination rates; use of the mass spectrometer as a continuous gas analyzer. J. clin. Invest. 1950, 29, 577.

2. Jones, H. B. Respiratory system: Nitrogen elimination in Medical Physics, O. Glasser Ed. Chicago, Year Book Publishers, 1950, vol. II, p. 855.

3. Fowler, W. S., Cornish, E. R., and Kety, S. S. Lung function studies. VIII. Analysis of alveolar ventilation by pulmonary $\mathrm{N}_{2}$ clearance curves. J. clin. Invest. 1952, 31, 40.

4. Briscoe, W. A. A method for dealing with data concerning uneven ventilation of the lung and its effects on blood gas transfer. J. appl. Physiol. 1959, 14, 291.

5. Briscoe, W. A. Comparison between alveolo-arterial gradient predicted from mixing studies and the observed gradient. J. appl. Physiol. 1959, 14, 299.

6. Briscoe, W. A., Cree, E. M., Filler, J., Houssay, H. E. J., and Cournand, A. Interrelationships between lung volume, alveolar ventilation and perfusion in chronic pulmonary emphysema. J. appl. Physiol. In press.

7. Briscoe, W. A., Hardewig, A., Emmanuel, G., Gurtner, H. P., Rochester, D., and Cournand, A. The distribution of blood perfusion to the lung in emphysema. Fed. Proc. 1959, 18, 16.

8. Chidsey, C. A., III, Fritts, H. W., Jr., Hardewig, A., Richards, D. W., and Cournand, A. The fate of radioactive krypton $\left(\mathrm{Kr}^{85}\right)$ introduced intravenously in man. J. appl. Physiol. 1959, 14, 63.

9. Hardewig, A., Rochester, D. F., and Briscoe, W. A. Measurement of solubility-coefficients of krypton in water, plasma and human blood, using radioactive $\mathrm{Kr}^{85}$. J. appl. Physiol. In press.

10. Robertson, J. S. Theory and use of tracers in determining transfer rates in biological systems. Physiol. Rev. 1957, 37, 133.

11. Robertson, J. S., Tosteson, D. C., and Gamble, J. L., $\mathrm{Jr}$. The determination of exchange rates in threecompartment steady-state closed systems through the use of tracers. J. Lab. clin. Med. 1957, 49, 497.

12. Steele, R. Retention of metabolic radioactive carbonate. Biochem. J. 1955, 60, 447.

13. Skinner, S. M., Clark, R. E., Baker, N., and Shipley, R. A. Complete solution of the three-compartment model in steady state after single injection of radioactive tracer. Amer. J. Physiol. 1959, 196, 238.

14. Lewallen, C. G., Berman, M., and Rall, J. E. Studies of iodoalbumin metabolism. I. A mathematical approach to the kinetics. J. clin. Invest. 1959, 38, 66.

15. Forster, R. E. Exchange of gases between alveolar air and pulmonary capillary blood: Pulmonary diffusing capacity. Physiol. Rev. 1957, 37, 391.

16. Kety, S. S. Theory and application of exchange of inert gas at lungs and tissues. Pharmacol. Rev. 1951, 3, 1.

17. Ayers, F. Theory and Problems of Differential Equations. New York, Schaum Publishing Co., 1952.

18. Fowler, W. S. Lung function studies. II. The respiratory dead space. Amer. J. Physiol. 1948, 154, 405. 